\title{
Diversity of Dehydrins in Oleae europaea Plants Exposed to Stress
}

\author{
Manuela Tripepi ${ }^{1,2}$, Mechthild Pöhlschroder ${ }^{2}$ and Maria Beatrice Bitonti ${ }^{1, *}$ \\ ${ }^{1}$ University of Calabria, Department of Ecology, Ponte P. Bucci, Cubo 6B, 87030, Arcavacata di Rende (CS), Italy \\ ${ }^{2}$ University of Pennsylvania, Department of Biology, 201 Leidy Laboratories, Philadelphia, PA 19104 USA
}

\begin{abstract}
Dehydrins (DHNs) belong to a large family of proteins whose expression is associated with dehydration during seed maturation, pollen grain development and bud dormancy during winter, as well as plant adaptive response to various stressors. However, the exact roles played by different members of this protein family have not been fully defined. To gain a better understanding of DHN functions in olive plants, we used Western blot analyses to investigate their expression in the leaves of olive plants subjected to wounding, water-deprivation and salt-treatment. Two prominent bands having molecular masses of approximately $40 \mathrm{kD}$ and $42 \mathrm{kD}$ were constitutively expressed, however, their levels increased when the leaves were exposed to stress. Dehydration and salt stress also resulted in the accumulation of two additional proteins, which had molecular masses of approximately $16 \mathrm{kDa}$ and $18 \mathrm{kD}$. These additional proteins were not detected following wounding. Our results suggest a physiological function for DHNs in olive plants during normal growth conditions and specialized functions during responses to certain types of stress.
\end{abstract}

Keywords: Leaf, stress factor, Dehydrin, Olea europaea cv Leccino.

\section{INTRODUCTION}

Environmental conditions, especially water availability, strongly influence plant productivity and health [1-3]. Therefore, to counteract the stress caused by water deficiency, land plants have commonly acquired adaptive mechanisms at the morphological, cellular and molecular levels that confer a selective advantage during times of drought [4-7]. These adaptive mechanisms include enhanced expression of a large set of genes that encode hydrophilic proteins $[8,9]$. Phylogenetically widespread, these proteins may confer a high hydration capacity. Chief among these proteins are the highly hydrophilic LEA polypeptides [9-12]. First described in plants, LEA-related proteins have since been identified in bacteria as well as invertebrates [8, 13-15]. The large group two LEA proteins, originally designated as the D-11 family, are also known as the Dehydrins (DHNs) [10], and are the best studied of the drought-induced watersoluble plant proteins $[9,16-20]$.

DHNs have molecular masses that range from 9 to 200 kilo dalton $(\mathrm{kD})$ and belong to five different subgroups, with each subgroup suggested to exhibit distinct functions [9- 10, 16-17, 21-23]. Overall, DHNs are intrinsically unstructured proteins, and, as such, may exhibit high flexibility, structural adaptability and extended conformations [24-27]. Consistent with these characteristics, recent studies suggest numerous activities for DHNs, including buffering water, sequestering ions, stabilizing membranes, or acting as chaperones or molecular shields $[9,19,28-31]$.

*Address correspondence to this author at the University of Calabria, Department of Ecology, Laboratory of Citofisiologia Vegetale, Ponte P. Bucci, Cubo 6B, 87030, Arcavacata di Rende, Cosenza, Italy;

Tel: +39 0984 492965; Fax: +390984 492986;

E-mail: b.bitonti@unical.it
In unstressed plants, DHNs accumulate in organs that undergo programmed functional dehydration, primarily in embryos during the late phase of embryogenesis, but also in the pollen grains $[21,32,33]$. DHNs also accumulate in the apices of some trees during bud dormancy, a period during which buds undergo wintertime dehydration [33]. In addition, DHNs are expressed in nearly all vegetative tissues during normal growth conditions and/or accumulate to high levels following exposure to stress, as observed in numerous independent studies on responses to drought, cold acclimation, salinity and ABA as well as during overexposure to light [9-10, 34-42]. In accordance with these findings, data from in vitro experiments have shown that DHNs are involved in stress responses that range from protection against water deprivation and extreme cold to detoxification and hydroxyl radical scavenging $[9,10,43]$. Based on this broad range of functions, DHNs may play a significant physiological role in the adaptive responses of plants. In this context, it is notable that, due in part to their sessile nature, plants are commonly subjected to various types of abiotic environmental stresses as well as to physical damage, commonly referred to as wounding, caused by, among other things, insects and severe weather.

Olea europaea is a member of the Oleaceae family and represents one of the emblematic and widespread crop species in the Mediterranean basin. As crops, these plants have a strong impact on both economy and on human health [44]. The olive plant is an evergreen, schlerophyll tree that is a drought-resistant and moderately salt-tolerant species $[45$, 46]. The tolerance of olive plants to mild-to-moderate water stress involves active and passive osmotic adjustments, which assure the maintenance of an adequate leaf turgor and gas-exchange rate. However, severe water stress, which in the field is often coupled to high levels of irradiation, strongly impairs photosynthetic activity through both the 
reduction of stomatic conductance and photo-inhibition [47]. In order to add further insights into the molecular mechanisms underlying olive drought resistance, the present work was carried out to investigate whether DHNs play a role in the stress response of olive plants to water deprivation, salt stress and wounding. The results generated during this study might aid in the development of more successful growth strategies for this unique oil tree species in geographic areas at risk of desertification due to both climate change and intensive land utilization.

\section{MATERIALS AND METHODS}

\section{Plant Materials and Growth Conditions}

Two-year-old plants of Olea europaea L. cv Leccino were purchased from Santa Cruz Olive Tree Nursery (Watsonville, CA 95077). Plants were acclimated for 30 days in the University of Pennsylvania Greenhouse at a temperature of $28^{\circ} \mathrm{C}$, at $100 \mu \mathrm{mol} \mathrm{m} \mathrm{m}^{-2} \mathrm{~s}^{-1}$ PAR, under a 16/18 hr light/dark regime and 50\% relative humidity. Plants were irrigated daily.

\section{Stress Treatments}

After acclimation, plants were divided into subgroups and exposed to different stresses. For drought stress, plants $(n=5)$ were progressively deprived of water as described by Tommasini et al. [48]. Leaf samples were collected from primary and secondary shoots at the beginning of the stress treatment (T0) and after 5, 10 and 15 days (T5, T10, T15).

For salt stress, plants $(n=5)$ were supplied with $50 \mathrm{mM}$ $\mathrm{NaCl}$ per day to a final concentration of $200 \mathrm{mM} \mathrm{NaCl}$. Final salt concentrations were reached gradually to avoid salt shock. Leaf samples were collected from primary and secondary shoots at the beginning of the stress treatment (T0) and after 5, 10 and 15 days (T5, T10, T15) of stress exposure.

Wounding stress was imposed on plants $(n=5)$ by cutting a small apical portion from the leaves of primary and secondary shoots. Wounded leaves were then collected after $5 \mathrm{~min}, 30 \mathrm{~min}, 1 \mathrm{hr}$ and $24 \mathrm{hr}$ after cutting.

\section{Protein Extraction and Western Blot Analysis}

Total protein was extracted as described by Wang et al. [49]. Briefly, olive leaves were pulverized in liquid nitrogen, $0.2 \mathrm{~g}$ of powered tissue was washed extensively with acetone and tricholoroacetic acid and then extracted using a phenolbased method. Protein concentrations were quantified using the Bio-Rad ${ }^{\mathrm{TM}}$ protein assay.

All protein samples were stored in NuPAGE lithium dodecyl sulfate sample buffer supplemented with $50 \mathrm{mM}$ dithiothreitol. Samples were run on Bis-Tris NuPAGE gels (Invitrogen $®$ ) under denaturing conditions, using morpholinepropanesulfonic acid (MOPS). Finally, proteins were transferred to polyvinylidene difluoride membranes by a Transblot-SD semidry transfer cell (Bio-Rad) at $15 \mathrm{~V}$ for 30 min using three different buffers: anode I (300 mM Tris, $10 \%$ [vol/vol] methanol, $\mathrm{pH} 10.4$ ), anode II (25 mM Tris, $10 \%$ [vol/vol] methanol, $\mathrm{pH} \mathrm{10.4),} \mathrm{and} \mathrm{cathode} \mathrm{(25} \mathrm{mM} \mathrm{Tris,}$ $40 \mathrm{mM}$ glycine, and 10\% [vol/vol] methanol, $\mathrm{pH} 9.4)$. Polyvinylidene difluoride membranes were incubated with the primary anti-plant dehydrin polyclonal antibody raised against the conserved dehydrin K-segment (TGEKKGIMDKIKEKLPGQH), (StressGen ${ }^{\mathrm{TM}}$, San Diego, CA) $(1: 1,000)$, and then with anti-rabbit secondary antibodies $(1: 10,000)$. The K-segment synthetic peptide, kindly provided by Dr. T.J. Close, was used during preincubation of the antiserum to confirm that the bands detected by Western blots were specifically recognized by the antigen-binding site of the anti-peptide antibody [50].

\section{RESULTS}

\section{Macroscopic Effects of Water Stress on Olive Leaves}

Under standard conditions, the leaves of olive plants are fully expanded to allow optimal light harvesting (Fig. 1A). Conversely, leaves of olive plants subjected to water deprivation exhibited an evident leaf rolling after 7 days (Fig. 1B) and showed the most pronounced leaf rolling after 15 days of water deprivation (Fig. 1C).
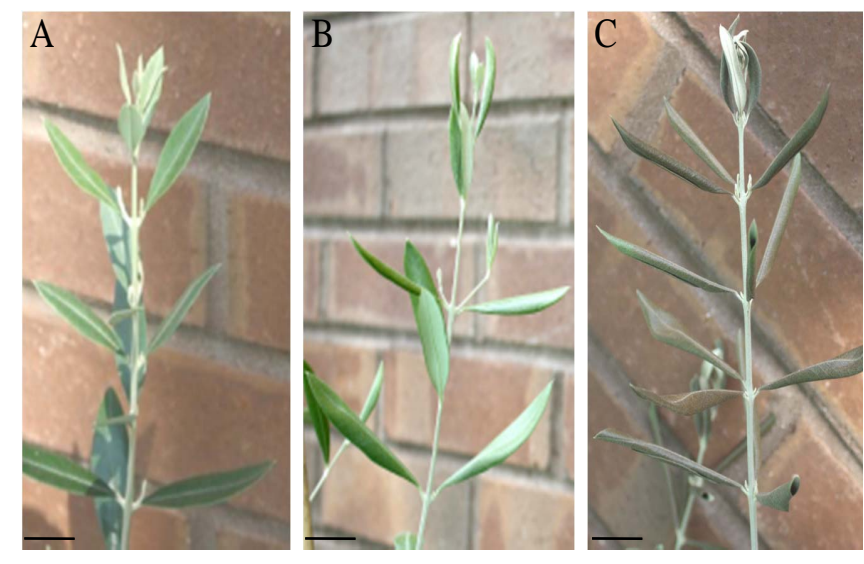

Fig. (1). Macroscopic leaf rolling of Olea europaea upon waterdeprivation. Two-year-old Olea europaea L. cv Leccino plants were grown under standard conditions (A) and deprived of water for 7 (B) and 15 (C) days. A macroscopic leaf rolling is evident in the drought stressed plant $(\mathbf{B}, \mathbf{C})$. Bars: $2 \mathrm{~cm}$.

Similar effects were also observed in salt-stressed plants where upon 4 days of exposure leaf rolling became evident and more extensive leaf rolling occurred after 10 days (data not shown).

\section{DHNs are Constitutively Expressed}

DHNs belong to a diverse family of hydrophobic proteins that are expressed under dehydration conditions. However, certain proteins belonging to this family are also expressed when no stress is present. Taking advantage of the fact that all proteins within this family contain the conserved $\mathrm{K}$ segment domain, we performed Western blot analyses of olive DHN diversity under stressed and unstressed conditions using an antibody raised against the K-segment.

Two bands, corresponding to polypeptides with molecular weights of approximately $40 \mathrm{kD}$ and $42 \mathrm{kD}$, were detected in protein extracts from the leaves of plants grown under non-stressed conditions (T0), suggesting low-level constitutive expression of some DHNs (Fig. 2A, B). 

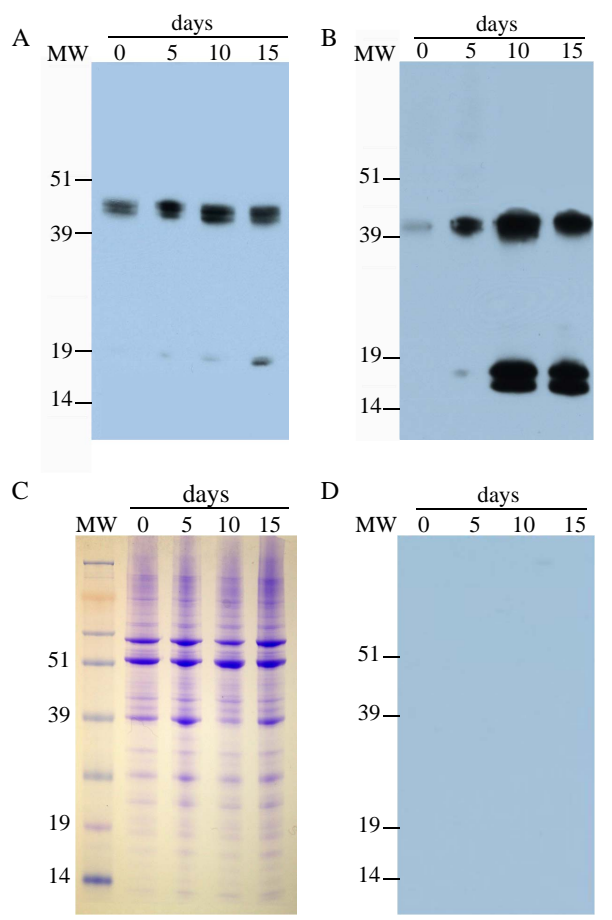

Fig. (2). Expression of olive DHNs under standard conditions and dehydration or salt stress. Immunoblot analysis of soluble leaf proteins from olive plants grown under progressive water deprivation (A), or subjected to salt stress treatment by adding $\mathrm{NaCl}$ to a final concentration of $200 \mathrm{mM}(\mathbf{B})$. Equivalent amounts of protein were subjected to LDS-PAGE and visualized by immunoblotting using an anti-DHN K-segment antibody. Gel containing soluble leaf proteins from olive plants subjected to salt stress stained with Coomassie-Blue to ensure quality of the extraction procedure and equal loading of protein samples (C). Immunoblot analysis of soluble leaf proteins from olive plants subjected to salt stress performed with antibodies pre-incubated with a synthetic K-segment (D).The sizes of protein standards are indicated on the left.

\section{Drought and Salt Stress Appear to Exhibit Distinct DHN Expression Patterns from Non-Stressed Leaves}

Western blot analysis of protein extracts from leaves of water-deprived olive plants showed increased abundance of two protein bands that were identified in extracts from the non-stressed leaves (Fig. 2A). Moreover, two additional bands, corresponding to polypeptides having molecular weights of approximately $16 \mathrm{kD}$ and $18 \mathrm{kD}$, were detected in olive leave protein extracts 5 days into the drought treatment (Fig. 2A).

Leaves exposed to salt stress also showed increased abundance of the higher molecular weight DHNs on day 5 of the treatment. However, distinct from dehydration-stress, the leaves from plants exposed to salt contained a considerably larger amount of these proteins at later stages (10 and 15 days). Even more pronounced was the amount of the smaller molecular weight DHNs in salt-stressed compared to waterdeprived plants (Fig. 2A, B). We confirmed that similar amounts of total protein were loaded in each experiment using coomassie blue staining (Fig. 2C and data not shown).

To confirm that the bands detected by Western blots were specifically recognized by the antigen-binding site of the anti-peptide antibody, we performed Western blot analysis using an immune serum pre-incubated with a synthetic K-segment. Consistent with antibody recognition of the $\mathrm{K}$-segment in the leave preparation, no labeled bands were detected under these conditions (Fig. 2D).

\section{DHN Expression Pattern of Wounded Leaves Appear to be Unique}

The abundance and diversity of DHNs were also investigated by Western blot analysis of protein extracts from olive leaves subjected to wounding, as described above (Fig. 3A). Similar to salt and dehydration stress, the higher molecular weight DHNs were more abundant following stress. Higher levels of these proteins were apparent within 30 minutes of wounding and increased over time, peaking at approximately 24 hours post-wounding. Interestingly, this stress condition did not result in the presence of the lower molecular weight DHNs (Fig. 3B).

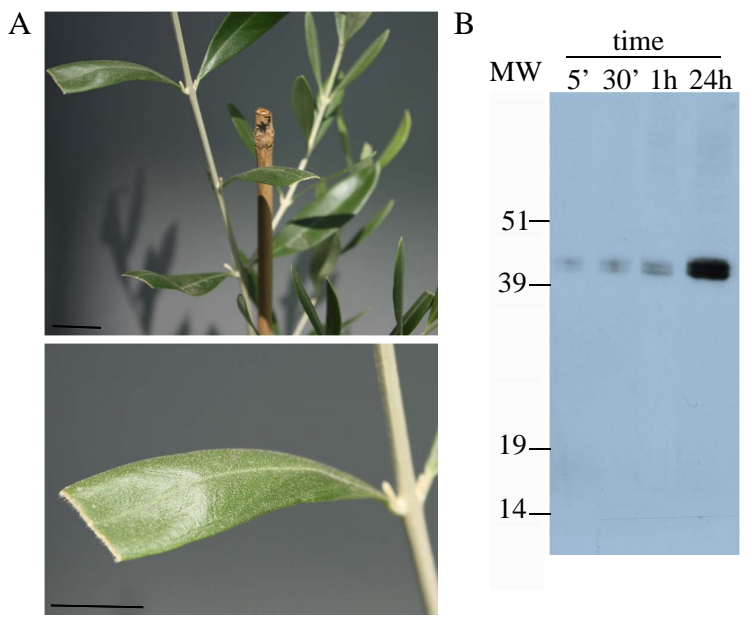

Fig. (3). Expression of olive DHNs upon wounding. Immunoblot analysis of soluble leaf proteins from olive plants subjected to a wounding stress. Equivalent amounts of protein were subjected to SDS-PAGE and visualized by immunoblotting using an antiDHN K-segment antibody (B). The sizes of protein standards are indicated on the left.

\section{DISCUSSION}

DHNs are a family of closely related proteins that have been shown to accumulate in vegetative tissues of plants exposed to various stressors $[9,10]$. While some DHNs are expressed at basal levels in non-stressed cells, others appear to only be detectable in plant tissues that have been exposed to stress [9, 10, 39]. Western blot analysis of olive leave protein extracts, using anti-K-segment antibodies, strongly suggest the upregulation of two constitutively expressed putative DHNs when the plants are subjected to drought, salt stress or wounding. These results are also in line with the multifunctional role proposed for DHNs spanning from protection against drought and extreme cold to detoxification and hydroxyl radical scavenging [9, 10, 43]. In this respect it is worth noting that wounding, which frequently occurs in plant organs as a consequence of insect feeding, is generally coupled to an immediate oxidative burst in damaged tissues [51-53]. Thus, the very early increase in levels of DHNs that we observed in wounded leaves may be consistent with radical scavenging activity [54]. The increased levels of 
these two proteins demonstrates that their abundance is modulated by stress and also supports the notion that the bands detected on Western blots by anti-K-segment antibodies are indeed DHNs.

Moreover, the stress-related increase in DHNs is higher in the leaves of salt-treated compared to both water deprived and wounded leaves. One explanation for such differential accumulation might be related to the primary function of DHNs as regulators of cell osmotic potential as demonstrated in various tissues of Arabidopsis thaliana [39]. In this context, it is interesting to note that the wheat LEA (group 1) protein Em demonstrates osmo-protective activity when expressed in yeast [55], and that a shorter lag period is observed in yeast cells expressing the barley LEA (group 3) gene HVAl when the yeast are transferred to a medium containing $1.2 \mathrm{M} \mathrm{NaCl}$ [56].

Notably, two additional putative DHNs of approximately $16 \mathrm{kD}$ and $18 \mathrm{kD}$ are expressed in the leaves of olive plants following either water deprivation or salt treatment, while they are not detected in either unstressed leaves or wounded leaves. Thus, specific DHN members seem to be involved in the dehydration/osmotic stress response in olive plants and might account for the drought and salt tolerance of such relevant schlerophyll species. This assumption is supported by data showing that under conditions of water deficit, transcription of $D H N$ genes is significantly higher in drought-tolerant than in drought-sensitive species. A correlation between plant drought tolerance and DHN accumulation was also found in sorghum and in sunflowers plants [57, 58]. Moreover, in salt-tolerant lines of rice, the level of ABA-induced expression of DHNs is significantly higher than it is in sensitive plants [59]. A direct interrelationship between the level of DHNs and cold tolerance has also been observed [60-62].

In summary, this is the first report presenting data strongly suggesting the involvement of DHNs in the molecular mechanisms of stress response in Olea europaea, a traditional tree crop of the Mediterranean basin, which has a world-wide impact as a food product as well as having positive effects on human health. As many as four different members belonging to large DHNs family appear to be expressed in olive leaves and a functional specialization for osmotic stress response was highlighted for two of the detected DHNs. Efforts are underway to clone the genes encoding the DHNs expressed in the olive leaves. Cloning these genes may also lead to identification of additional DHNs that are expressed under other conditions. Further investigation will be necessary to fully define the expression patterns of various DHN members in the different organs of the olive plant, with our focus being on proteins expressed in the fruit, which is frequently exposed to a variety of pathogens $[44,63]$. Based on the results of the present work, we show that DHNs may serve as integral components of olive plant responses to stressful conditions that strongly impact both plant productivity and product quality.

\section{ACKNOWLEDGEMENTS}

The authors acknowledge Dr. T.J. Close (University of California) who kindly provided purified protein. This work was supported by a National Science Foundation grant (reference MCB02-39215) and MATTM grant (Italy). We thank Tracy Byford for providing space in the University of Pennsylvania Greenhouse.

\section{REFERENCES}

[1] Basile B, Marsal J, DeJong TM. Daily shoot extension growth of peach trees growing on rootsstocks that reduce scion growth is related to daily dinamics of stem water potential. Tree Physiol 2003; 10: 695-704.

[2] Alpert P. The limits and frontiers of desiccation-tolerant life. Integr Comp Biol 2005; 45: 685-95.

[3] Bray EA. Plant responses to water deficit. Trends Plant Sci 1997; 2: $48-54$

[4] Ingram J, Bartels D. The molecular basis of dehydration tolerance in plants. Annu Rev Plant Biol 1996; 47: 337-403.

[5] Oliver MJ, Tuba Z, Mishler BD. The evolution of vegetative desiccation tolerance in land plants. Plant Ecol 2000; 151: 85-100.

[6] Bartels D, Souer E. Molecular response of higher plants to dehydration. Top Curr Genet 2003; 4: 9-38.

[7] Proctor MCF, Oliver MJ, Wood AJ, et al. Desiccation-tolerance in bryophytes: a review. Bryologist 2007; 110: 595-621.

[8] Garay-Arroyo A, Colmenero-Flores JM, Garciarrubio A, et al. Highly hydrophilic proteins in prokaryotes and eukaryotes are common during conditions of water deficit. J Biol Chem 2000; 275: 5668-74.

[9] Rorat T. Plant dehydrins--tissue location, structure and function. Cell Mol Biol Lett 2006; 11: 536-56.

[10] Battaglia M, Oliera-Carrillo Y, Garciarrubio A, et al. The enigmatic LEA proteins and other hydrophilins. Plant Physiol 2008; 148: 6-24.

[11] Dure L, Chlan C. Developmental biochemistry of cottonseed embryogenesis and germination. XII. Purification and properties of principal storage proteins. Plant Physiol 1981; 68: 180-6.

[12] Hundertmark M, Hincha DK. LEA (Late Embryogenesis Abundant) proteins and their encoding genes in Arabidopsis thaliana. BMC Genomics 2008; 9: 118-39.

[13] Battista JR, Park M-J, McLemore AE. Inactivation of two homologues of proteins presumed to be involved in the desiccation tolerance of plants sensitizes Deinococcus radiodurans RI to desiccation. Cryobiology 2001; 43: 133-9.

[14] Browne J, Tunnacliffe A, Burnell A. Plant desication gene found in a nematode. Nature 2002; 416: 38 .

[15] Gal Tz, Blazer I, Voltai H. An LEA group 3 family member is involved in survival of $\mathrm{C}$. elegans during exposure to stress. FEBS Lett 2004; 577: 21-6.

[16] Kyosue T, Yamaguchi-Shinozaki K, Shinozaki K. Cloning of cDNAs for genes that are early-responsive to dehydration stress (ERDs) in Arabidopsis thaliana. Plant Mol Biol 1994; 25: 791-8.

[17] Close TJ, Dehydrins: Emergence of a biochemical role of a family of plant dehydration proteins. Physiol Plant 1996; 97: 795-803.

[18] Campbell SA and Close TJ. Dehydrins: Genes, Proteins, and Associations with Phenotypic Traits. New Phytol 1997; 137: 61-74.

[19] Tunnacliffe A. Wise MJ. The continuing conundrum of the LEA proteins. Naturwissenschaften 2007; 94: 791-812.

[20] Layton B, Boyd MB, Tripepi M, et al., "Dehydration-induced expression of a 31-kda dehydrin in Polypodium polypodioides (Polypodiaceae) may enable large, reversible deformation of cell walls". Am J Bot 2010; 4: 1-10.

[21] Dure LM, Crouch J, Harada T, et al. Common amino acid sequence domains among the LEA proteins of higher plants. Plant Mol Biol 1989; $12: 475-86$.

[22] Dure L. Structural motifs in LEA proteins. In TJ Close, EA Bray, eds, Plant responses to cellular dehydration during environmental stress. Am Soc Plant Physiol 2009, pp. 91-103.

[23] Campbell SA and Close TJ. Dehydrins: Genes, Proteins, and Associations with Phenotypic Traits. New Phytol 1997; 137: 61-74.

[24] Soulages JL, Kim K, Arrese EL, et al. Conformation of a group 2 late embryogenesis abundant protein from soybean: evidence of poly (L-proline)-type II structure. Plant Physiol 2003; 131: 963-75.

[25] Bokor M, Csizmok V, Kovacs D, et al. NMR relaxition studies on the hydrate layer of intrinsically unstructured proteins. Biophys $\mathrm{J}$ 2005; 88: 2030-7.

[26] Mouillon JM, Gustafsson P, Harryson P. Structural investigation of disordered stress proteins: comparison of full-length dehydrins with 
isolated peptides of their conserved segments. Plant Physiol 2006, 141: 638-50.

[27] Mouillon JM, Eriksson SK, Harryson P. Mimicking the plant-cell interior under water stress by macromolecular crowding: disordered dehydrin proteins are highly resistant to structural collapse. Plant Physiol 2008, 148: 1925-37.

[28] Koag MC, Fenton DR, Wilkens S, et al. The binding of maize DHN1 to lipid vesicles: gain of structure and lipid specifity. Plant Physiol 2003; 131: 309-16.

[29] Goyal K, Walton LJ, Tunnacliffe A. LEA proteins prevent protein aggregation due to water stress. Biochem J 2005; 388: 151-7.

[30] Kovacs D, Kalmar E, Torok Z, et al. Chaperone activity of ERD10 and ERD14, two disordered stress-related plant proteins. Plant Physiol 2008; 147: 381-90.

[31] Kruger C, Berkowitz O, Stephan UW, et al. A metal-binding member of the late embryogenesis abundant protein family transports iron in the phloem of Ricinus communis L. J Biol Chem 2002; 277: 25062-9.

[32] Ulrich TU, Wurtele ES, Nikolau BJ. Sequence of EMB-1, an mRNA accumulating specifically in embryos of carrot. Nucl Acids Res 1990; 18: 2826.

[33] Vicient CM, Gruber V, Delseny M. The Arabidopsis AtEm1 promoter is active in Brassica napus L. and is temporally and spatially regulated. J Exp Bot 2001; 52: 1587-91.

[34] Rinne P., Willing A, Kaikuranta P. Onset of freezing tolerance in birch (Betula pubescens Ehrh) involves LEA proteins and osmoregulation and is impaired in an ABA-deficient genotype. Plant Cell Environ 1998; 21: 601-11.

[35] Houde MJ, Danyluk JF, Laliberte E, et al. Cloning, characterization, and expression of a cDNA encoding a 50-kilodalton protein specifically induced by cold acclimation in wheat. Plant Physiol 1992; 99: 1381-7.

[36] Wood AJ, Goldsbrough PB. Characterization and expression of dehydrins in water stressed Sorghum bicolor. Physiol Plant 1997; 99: 144-52.

[37] Ismail AM, Hall AE, Close TJ.Allelic variation of a dehydrin gene cosegregates with chilling tolerance during seedling emergence. Proc Natl Acad Sci USA 1999; 96: 13566-70.

[38] Zhu B, Choi DW, Fenton R, et al. Expression of the barley dehydrin multigene family and the development of freezing tolerance. Mol Gen Genet 2000; 264: 145-53.

[39] Nylander M, Svensson J, Palva ET, et al. Stress-induced accumulation and tissue-specific localization of dehydrins in Arabidopsis thaliana. Plant Mol Biol 2001; 45: 263-79.

[40] Kimura M, Yamamoto YY, Seki M, et al. Identification of Arabidopsis genes regulated by high light-stress using cDNA microarray. Photochem Photobiol 2003; 77: 226-33.

[41] Kim SY, Nam KH. Physological roles of ERD10 in abiotic stresses and seed germination in Arabidopsis. Plant Cell Rep 2010; 29: 203-9.

[42] Borovskii GB, Stupnikova IV, Antipina AI, et al. Accumulation of dehydrin-like proteins in the mitochondria of cereals in response to cold, freezing, drought and ABA treatment. BMC Plant Biol 2002; 2: 5.

[43] Wisniewski M, Webb R, Balsamo R, et al. Purification, immunolocalization, cryoprotective, and antifreeze activity of PCA60: A dehydrin from peach (Prunus persica). Physiol Plant 2002; 105: 600-8.

[44] Loumou A, Giourga C. Olive groves: "The life and identity of the Mediterranean"'. Agricult Human Values 2003; 20: 87-95.

[45] Lo Gullo MA, and Salleo S. Different strategies of drought resistance in three Mediterranean sclerophyllous trees growing in the same environmental conditions. New Phytol 1988; 108: 267-76.
[46] Boussadia O, Mariem FB, Mechri B, et al. Response to drought of two olive tree cultivars (cv Koroneki and Meski). Sci Hort 2008; 116: 388-93.

[47] Angelopoulos KB, Dichio B, Xiloyannis C. Inhibition photosynthesis in olive trees (Olea europaea $\mathrm{L}$.) during water stress and rewatering. J Exp Bot 1996; 47: 1093-100.

[48] Tommasini L, Svensson JT, Rodriguez EM, et al. Dehydrin gene expression provides an indicator of low temperature and drought stress:trascriptome-based analysis of barley (Hordeum vulgare L.). Funct Integr Genomics 2008; 8: 387-405.

[49] Wang W, Scali M, Vignani R, et al. Protein extraction for twodimensional electrophoresis from olive leaf, a plant tissue containing high levels of interfering compounds. Electrophoresis 2003; $24: 2369-75$

[50] Olave-Concha N, Ruiz-Lara S, Munoz X, et al. Accumulation of dehydrin transcripts and proteins in response to abiotic stresses in Deschampsia antarctica. Ant Sci 2004; 16; 175-84.

[51] Baron C, Zambryski PCThe plant response in pathogenesis, symbiosis, and wounding: variations on a common theme? Ann Rev Genet 1995; 29: 107-29.

[52] Ebel J. Oligoglucoside elicitor-mediated activation of plant defense. Bio Essays 1998; 20: 569-76.

[53] Klessig DF, Durner J, Noad R, et al. Nitric oxide and salicylic acid signaling in plant defense. Proc Natl Acad Sci USA 2000; 97: 8849-55.

[54] Hara M, Fujinaga M, Kuboi T. Radical scavenging activity and oxidative modification of citrus dehydrin. Plant Physiol Biochem 2004; 42: 657-62.

[55] Swire-Clark GA and Marcotte WR. The wheat LEA protein Em functions as an osmoprotective molecule in Saccharomyces cerevisiae. Plant Mol Biol 1999; 39: 117-28

[56] Zhang L, Ohta A, Takagi M, et al. Expression of plant group 2 and group 3 lea genes in Saccharomyces cerevisiae revealed functional divergence among LEA proteins. J Biochem 2000; 127: 611-6.

[57] Wood AJ, and Goldsbrough PB. Characterization and expression of dehydrins in water-stressed Sorghum bicolor. Physiol Plant 1997; 99: $144-52$

[58] Cellier FG, Conejero J, Breitler C, et al. Molecular and physiological responses to water deficit in drought-tolerant and drought-sensitive lines of sunflower. Accumulation of dehydrin transcripts correlates with tolerance. Plant Physiol 1998; 116: 319-28

[59] Moons A, Bauw G, Prinsen E, et al. Molecular and physiological responses to abscisic acid and salts in roots of salt-sensitive and salt-tolerant Indica rice varieties. Plant Physiol 1995; 107: 177-86.

[60] Danyluk J, Houde M, Rassart E, et al. Differential expression of a gene encoding an acidic dehydrin in chilling sensitive and freezing tolerant Gramineae spewcies. FEBS Lett 1994; 344: 20-24.

[61] Robertson AJ, Weninger A, Wilen RW, et al. Comparison of dehydrin gene expression and freezing tolerance in bromus inermis and secale cereale grown in controlled environments, hydroponics, and the field. Plant Physiol 1994; 106: 1213-6.

[62] Zhu B, Choi DW, Fenton R, et al. Expression of the barley dehydrin multigene family and the development of freezing tolerance. Mol Gen Genet 2000; 264: 145-53.

[63] Burrack HJ, Zalom FG. Olive fruit fly (Diptera: Tephritidae) ovipositional preference and larval performance in several commercially important olive varieties in California. J Econ Entomol 2008; 101: 750-8. 